\title{
Emergent situations for smart cities: a survey
}

\author{
Ahmad Mohamad Al-Smadi ${ }^{1}$, Mutasem K. Alsmadi' ${ }^{2}$ AbdelKarim Baareh ${ }^{3}$, Ibrahim Almarashdeh ${ }^{4}$, \\ Hayam Abouelmagd ${ }^{5}$, Osman Saad Shidwan Ahmed ${ }^{6}$ \\ ${ }^{1,3}$ Department of Computer Science, Abalqa Applied University, Ajloun University College, Jordan \\ ${ }^{2,4}$ Department of Management Information Systems, College of Applied Studies and Community Service, \\ Imam Abdulrahman Bin Faisal University, Saudi Arabia \\ ${ }^{5}$ Curriculum and Method of Teaching, Libraries and Information Department, College of Arts, \\ Imam Abdulrahman Bin Faisal University, Saudi Arabia \\ ${ }^{6}$ Department of Business Administration, College of Applied Studies and Community Service, \\ Imam Abdulrahman Bin Faisal University, Saudi Arabia
}

\section{Article Info}

Article history:

Received Mar 1, 2019

Revised Jun 22, 2019

Accepted Jul 2, 2019

\section{Keywords:}

Cloud computing

Emergent situations

Fog computing

IoT

Smart cities

\begin{abstract}
A smart city is a community that uses communication and information technology to improve sustainability, livability, and feasibility. As any community, there are always unexpected emergencies, which must be treated to preserve the regular order. However, a smart system is needed to be able to respond effectively to these emergent situations. The contribution made in this survey is twofold. Firstly, it provides a comprehensive exhaustive and categorized overview of the existing surveys for smart cities. The categorization is based on several criteria such as structures, benefits, advantages, applications, challenges, issues, and future directions. Secondly, it aims to analyze several studies with respect to emergent situations and management to smart cities. The analysis is based on several factors such as the challenges and issues discussed, the solutions proposed, and opportunities for future research. The challenges include security, privacy, reliability, performance, scalability, heterogeneity, scheduling, resource management, and latency. Few studies have investigated the emergent situations of smart cities and despite the importance of latency factor for smart city applications, it is rarely discussed.
\end{abstract}

Copyright (c) 2019 Institute of Advanced Engineering and Science. All rights reserved.

\section{Corresponding Author:}

Ahmad Mohamad Al-Smadi,

Department of Computer Science, Abalqa Applied University,

Ajloun University College,

Ajloun, Jordan.

Email: amhs1966@bau.edu.jo

\section{INTRODUCTION}

The world citizens' percentage that inhabits in cities is over $50 \%$, by 2050 , this percentage will probably grow to 70 percent [1]. It is mandatory to build cities for the rising numbers of people with the required services, which gives rise to the idea of building smart cities that seek to adopt the life through constructing infrastructure with the use of information of communication technology (ICT) [2]. The conception of smart cities includes the city organization and management as a whole through technology. It is constructed and maintained by using integrated technologies, such as sensors, electronics, and networks. To improve the city services provided to the citizens and to improve the quality of their life, smart city services have shown a major motivation of investigation [3]. Some the latest ICT that are the essential component of the smart city are the cloud computing, Internet of things (IoT), smartphone technology, smart meters, semantic web, Radio Frequency Identification system and artificial intelligence. 
The IoT is the network of tangible objects embedded with computational devices, software, electronics, smart sensors and connectivity and connectivity enabling these objects to connect and exchange data $[4,5]$. Many services are currently broadly used with the implementation of IoT applications such as natural disasters for public safety [6,7]. The promising strengths of smart city paradigm face many prominent and challenges in the development of IoT applications [8]. The integration between sensors, human, mobile, and vehicles allows obtaining and analyzing information and inputs for some tasks in the paradigm of IoT and clouding computing $[6,9]$. Cloud computing is a model, that enables network access upon request to a pool that shared computing resources to outfit with scalable construction for data, application, and file storage [10].

The crucial advantages of cloud computing such as elasticity and scalability are the main challenging issues still faced in the research community [11]. There are inherent issues of cloud computing that prohibit a wide range of cloud computing application and services from popular benefits of computing. These issues include lack of mobility, lack of location awareness, and unacceptable latency [12]. One of the critical issues of cloud computing that have not been resolved yet is the unreliable latency. Other issues include location awareness and lack of mobility. Therefore, fog computing or edge computing can resolve these issues through elasticity of resources and services in distributed networks [13].

The fog clouding is a collective of loosely coupled, facultative and resources such as computers, data centers, etc. where the resources settle in at the network edge and are within short distance from the clients and sensors [14]. It is generally considered as cloud computing extension from the core network to the edge network. It is objective is to reduce latency on the data computation or aggregation while routing it to the central cloud for heavy computations [14]. The cloud computing platforms such as fog computing is required to handle big data streams in the resource-rich processing of data and low latency to be integrated with cloud computing and edge computing [7]. As fog computing paradigm promises and extends cloud computing for more improved services, its distinct characteristics face security and privacy issues. Cloud computing inherits these issues to fog computing [15]. Fog computing can address many concerns of cloud computing such as battery life, bandwidth cost, data privacy, and response time [16].

Relying on a literature review of studies published between 1990 and 2018, the technological revolution influenced everything [17-40], and the use of Artificial Intelligence (AI) algorithms is expansive, particularly in providing solution to challenging problems including analysis of medical image [41-45], nurse rostering problem [46], Healthcare Monitoring system [31, 47], prediction of river flow [48-50], patterns recognition and retrieval of information [51-62] and image segmentation [17, 18, 28, 63-69], Learning Management System [70, 71]. Accordingly, the ensuing results show that Internet of Things and Artificial Intelligence represent the most used technologies for smart cities [72].

Our objectives in revisiting the studies related smart cities are to learn more about the smart cities, to identify the related issues, and to highlight open challenges in purpose directing us to future research. In this paper, we will discuss several issues in smart city applications, by reviewing some of the existing workrelated work in underlying domains, to identify some issues. We carry out a theoretical-methodological approach to achieve the objectives of this study, by collecting related works about cloud computing, fog computing, IoT and smart city applications, reviewing literature conducted in fog computing and smart city applications, and comparing between previous studies against some criteria to distinguish the novelty of this survey paper. The criteria include the main topics, applications, structures, benefits, advantages, challenges and issues, and future directions. We reviewed several factors in each study such as the challenges and issues discussed, the solutions proposed, and opportunities for future research. The challenges include security, privacy, reliability, performance, scalability, heterogeneity, scheduling, resource management, and latency.

The structure of this research is as follows. Beside this section, the second section will review the related literature that gives an overview of cloud computing, fog computing, smart city, and emergency systems. The third is the section concerned with discussion and analysis shows comparison between the researchers reviewed in this research and analyses the results they contained. The differences between these studies are also discussed in order to show the contribution of new research. Finally, yet importantly, our conclusions and future works are presented in the fourth section.

\section{LITERATURE REVIEW}

Several Researches have been published, to formally define smart cities and the related challenges. Here we try to present some of the preceding researches which are near in some way from our study, surveys of previous studies are listed in the first subsection, the second subsection concerned with smart cities researches and some relevant subjects, and the last subsection focused on the emergent situations of smart cities.

Int J Elec \& Comp Eng, Vol. 9, No. 6, December 2019 : 4777 - 4787 


\subsection{Previous surveys}

In this section, we present some the previous surveys related to our study. Several researches have been published, to formally define the different types of computing and the related challenges, and issues. For instance, the authors in [73] have focused on the integration of cloud and IoT called CloudIoT including their properties, features, technologies, and open challenges. New applications, challenges, and open research opportunities also have been analyzed in detail under the CloudIoT paradigm. Similarly, the work in [74] includes a study of the integration of cloud computing and IoT that cope a lot of research for investigation. It describes the integration from the perspective of general architectures and applications. The authors in [75] created an action plan that outlines the literature about the social and technological components of IoT, big data, and clouds. The technology and user motivation play an essential role in the development of the smart city. Also, the authors in [12] presented and discussed different definitions of fog computing at the edge of the network as a promising infrastructure that provides elasticity of resources.

While the study in [7] included a review of many dimensions of the architecture, platforms, characteristics, applications, and abstractions of edge computing, fog computing, and eco-systems. Also, the physical properties, application mobility, runtime environment, privacy sensitivity, novel capabilities of edge and fog layers were highlighted. A network architecture and framework is proposed in [76] to achieve high levels of resilience based on cloud computing paradigm and RPL routing protocol. The work in [16] introduces a defined structure of edge computing including different cases of cloud computing. The provision of resources and services by the clouds has addressed in [77] a novel paradigm called fog computing to be provided outside of the cloud and closer to the end users and at the network edge. It is obvious that none of these previous surveys have reviewed the smart cities from emergency situations perspectives, and that will be our objective that to identify the smart city in emergent situations.

\subsection{Previous searches}

The increasing of cities population and the growth of the demands of required services have created a mandatory task of the researchers to examine the infrastructure of smart city environment proper to the population [2]. The trending paradigm of the smart city becomes popular in technological and strategic planning in the current environment. Many challenges should be overcome to qualify the city and then improve the residents' life.

Smart city concept is discussed in [78] and the data adopted to resolve the encountered issues and then improving the quality of the life of citizens. With the great amount, wide variety, and high speed of life requirements and city data, big data technologies received a valuable interest to utilize new mechanisms for better quality of life. The progress of smart city environments is discussed in [3] through reviewing the fundamentals of data processing and software platforms to support the integration and development of smart city services. On the other hand, it included some mechanisms to overcome the existing essential technologies and practical issues that limit the development of these platforms from wide implementation.

The authors in [79] presented a smart city concept that plays a vital role in industrial and academic fields in smart city technologies. The development of many middleware platforms and infrastructures of IoT have emerged distinguishable methods to create fragments of IoT eco-systems noticed for the communications among them. Also the study in [80] outlined smart city concepts, motivations, challenges, and applications. Further, it shows the main components and features of IoT technology provided to the smart city with practical experience. In the other hand, the authors in [16] introduced a defined structure of edge computing including different cases of smart city and smart homes. Mobile cloud services under the paradigm of smart city applications and projects are devoted in [81], in addition to data processing and storage transformed from local mobile devices to the clouds per mobile cloud computing paradigm. The researchers in [77] outlined the extent of cloud computing services that satisfy the objectives of smart grid eco-systems requirements due to the growth of the development of information technology applications such as intelligent transportation using smart devices. The infrastructure of IoT and sensor networks revealed the University of the online and active objects to outperform the traditional cloud deployment of resource time and dynamic nature of intelligent systems. In cloud platform, the authors in [6] provided information about the opportunities of analyzing data of geographic regions to save the life of people. The results of [82] show some patterns and the use of cloud-based solutions allow to manage and consolidate infrastructure for lower consumption of cost and electricity.

The authors in [76] aims to achieve a multi-layer recovery system using smart objects located at the lower layer of the architecture. These objects interact with each other through virtual gateways and across RPL protocol. It uses the fog of the cloud for virtual gateways in the edge of the network to enable easier access to the internet. At higher layers, data is collected to have an insight of the IoT infrastructure for multilayer systems. The disaster management based on fog computing is one of the proposed models in IoT 
platforms. In addition, the mechanism of this model depends on IoT data and fog computing real-time applications [82].

The applications, facilities of abstraction, implementations, and the distributed nature of multiple providers of cloud IoT are involved in [83]. The study in [81] explains the access to these services becomes available as a vital feature of mobile cloud services. The mobile terminal is used as the main source of data collection. The study also focuses on the criteria used to select mobile cloud services. Further, the projects and implementations of CloudIoT are included and the future directions and the leading roles of CloudIoT environment [73]. Where, the authors in [84] discussed many opportunities to improve the quality of life by improving the present environment of cyber-physical system and existing services as well as the associated challenges, concerns, and future trends. Furthermore, the study in [85] involved a discussion about the characteristics of fog computing in addition to the future research opportunities and concerning challenges. Research in [73] critically reviewed the literature work and surveyed fog computing architectures and algorithms.

Further, the emerging technologies and lessons learned are reviewed by [77] within the role of fog computing. Additionally, the study in [75] includes an implementation and evaluation of a prototype of fog computing. A reference architecture is derived by [3] to direct the progress of the future developments and platforms of the smart city. The valuable data, processing steps, and big data applications and platforms are also involved in the study [78]. Different applications of cloud computing integrated with IoT are detailed in [74] and compared in terms of architecture model, service model, algorithms used, protocols applied, and database technologies. However, it does not security aspect of the data transfer from cloud resources to IoT applications. Moreover, the potential applications of cloud IoT architecture is elaborated by [83] including the intelligent transportation systems, smart cities, environment tracking etc. Real world examples, datadriven, practical applications, and the smart energy domains are shown in [78] with respect to data visualization, smart traffic systems, and smart public safety.

The smart city vision provides main requirements and information about the advantages of integrated services of cloud and IoT. In addition to the relevant challenges are discussed in [79]. The study in [3] includes a monitor of air quality to analyze the behavior of carbon track. In addition, the architecture of the smart city is tested in [86] using IoT in terms of security threats. Further, some good practices of smart city security are described by [86] from the perspective of different stakeholders of smart city and the performance of each solution.

Data security and privacy layers support the infrastructure of data management techniques and computing and networking technologies to improve smart city are shown by [87]. It also covered many lessons learned, limitations, challenges, achievements, and aspects of the smart city. However, the proposed architecture of [76] needs to be described in more details. It also needs to provide end to end resilience for the environment to develop the smart city and cloud services. Therefore, more concerning aspects include flexibility, reliability, resilience, and security have to be discussed.

Moreover, the authors in [15] highlights the privacy issues including location privacy, user privacy and data privacy that require developing new solutions to adapt these changes and challenges. In addition, the research directions and open challenges of fog computing are focused in [73]. Furthermore, the main opportunities of fog-based smart grid computing development and the key challenges and research drives to make fog computing success and viable are included in [77]. In addition, the challenges and goals of fog computing platform are analyzed by [75] including the design of different applications.

\subsection{Emergent situations in smart cities}

The key objective of smart cities is to provide a high-quality life for citizens, and this goal can't be achieved without taking in considerations the emergent situations, respond to these situations, survive citizens, and supply to them more efficient and safe routes. Several studies give some attention to this field. For example; the authors in [88] discussed the possible challenges that faced smart cities and provide a pre-disaster plan for building all smart cities infrastructure be disaster resilience and fire protection. In the same manner, also the study in [89] explored several issues in the occasion of residing citizens in smart cities, such as the emergency response, and encourage the process of plan drawing to ensure that smart city is robust. Where, the authors in [90] study smart city emergent systems in regarding to the real-time and distributed emergency recourses, schedule these resources in a way that maximize the resource quality and minimize cost and time by using Hierarchy Particle Swarm Optimization Algorithm (HPSO), in addition to construct emergency architecture that consists of the following layers: resource, network, sense, smart service, and application. On the other hand, the study in [91] managed emergent situations in the smart city by using the smart signal that analyses situations, integrate with IoT, share information and it must be aware of its contents. Also, the authors in [92] proposed a semi-Markov model in smart cities to capture the probable dynamics events succeed an earthquake, this model supposed to quantify hazard rate and 
estimate the restoration time, this model implemented by dynamic programming, it considering suitable in the smart city because that in these cities the data followed events are recorded.

However, the study in [93] aimed to develop emergency response systems for disasters of various scales concentrate on transportation systems, by using Vehicular Ad-hoc Networks (VANETs), mobile and Cloud Computing technologies and based on demand and speed strategies. While, the authors in [94] suggested system composed of a central agent and the three layers located over different dimensions, unmanned aerial vehicle (UAV) layer, multi-robot layer and sensor network layer. UAV collects data from air, where on the ground there are robots that dealing with emergencies, and the sensor network layer helping the previous layers to accomplish the required tasks. With the same goal, the authors in [95] proposed an architecture of emergency response system in order to improve the response event in smart cities, this is done by enabling the information from emergency site to service provider, this system depends on smart building supplied with the facilities of motion detection, tracking, and sensing system, LAN server collect this information, then the emergency service provider hosts the smart building information. Lastly; the study in [96] designed traffic control system to improve the emergency response in smart cities, by changing the control of network routes, and driving policies. It aims to reduce emergency vehicles response time, and determine the emergency level, by using the fuzzy Logic controller that needs the traffic parameters, and upon certain functionality and routing techniques choose the suitable actions. The latency sensitive applications demand fast response of real-time applications and the distance between cloud and end user devices or terminals in [11] involve several issues to many applications such as content delivery and disaster management applications. Whereas; the authors in [77] presents a description of fog-based computing architectures and the applicability of algorithms to support cloud computing and enable new trends of real-time applications in terms of latency. The emergent discussed, proposed approach and the related issues are summarized in Table 1.

Table 1. Summary of emergent situations of smart cities literatures

\begin{tabular}{|c|c|c|c|}
\hline Reference & Emergent & Proposed Approach & Related Issues \\
\hline$[88]$ & Earthquake & Fire Protection & Security \\
\hline [88] & Disaster & Pre-disaster plan & Delivery \\
\hline [89] & $\begin{array}{l}\text { Climate Change } \\
\text { and Disaster }\end{array}$ & Pre-disaster plan & $\begin{array}{l}\text { Sustainable energy and } \\
\text { mobility }\end{array}$ \\
\hline [90] & & $\begin{array}{l}\text { Emergency management by recourses, scheduling } \\
\text { HPSO }\end{array}$ & $\begin{array}{l}\text { Real time aware, Distributed, } \\
\text { Self-organization, } \\
\text { Response time, Heterogeneous }\end{array}$ \\
\hline [91] & & Smart signal & $\begin{array}{l}\text { Energy consumption, Response } \\
\text { time }\end{array}$ \\
\hline [92] & Earthquake & Semi-Markov model & Safety, Response time \\
\hline [93] & Disasters & $\begin{array}{l}\text { Emergency response systems } \\
\text { (VANETs and mobile) }\end{array}$ & Response time and Speed \\
\hline [94] & & $\begin{array}{l}\text { Central agent and three layers: unmanned aerial vehicle } \\
\text { layer, multi-robot layer and sensor network layer. }\end{array}$ & Localization, Safety, Security \\
\hline [95] & & $\begin{array}{l}\text { Emergency response system(motion detection, tracking, } \\
\text { and sensing system, LAN server) }\end{array}$ & Security and Privacy \\
\hline [96] & & Fuzzy Logic based System & Congestion, Response time \\
\hline
\end{tabular}

\section{DISCUSSION AND COMPARISON}

This section shows the findings from reviewing the above-related works. Table 2 shows the categorization of the investigated related works in terms of main issues discussed, main structures included, and main future subjects suggested. The authors in [85] discussed fog computing, cloudlets, and mobile edge computing. The main issues that are discussed in [85] are High latency, non-adaptive machine, and low spectral efficiency. The study in [73] presents a survey of cloud IoT and the main properties, features, technologies, and open challenges for future research. In addition, new application, challenges and leading roles of fog computing are discussed. The study in [84] also shows IoT cloud-based infrastructure, demands, and services. Moreover, the study in [84] includes an overview of the fast development and technologies in terms of their challenges, concerns, and solutions against issues. Similarly, the authors in [3] provide a review of the IoT and cloud computing technologies, functional requirements and categories of the current practical issues of data processing. It also shows open research issues and future trends of the smart city. The energy efficiency, performance, and reduced latency are considered by [83] for fog nodes of the architecture of smart router. The study in [83] also offers the applications, facilities, abstractions, and implementation of fog applications. The authors in [79] and [6] have shown the paradigms of IoT and clouds to understand the opportunities and solutions for save life and smart city applications. They also provided fog computing services and the main platforms and infrastructures for cloud and IoT to support the smart city. 
Finally, the authors in $[7,11,77]$ have presented Fog-based computing architectures and the applicability of algorithms to support cloud computing and enable new trends of real-time applications. In addition, they analyze latency sensitive applications demand fast response of real-time application.

Table 2. The categorization of the investigated related works in terms of main issues discussed, main structures included, and main future subjects suggested

\begin{tabular}{|c|c|c|c|c|}
\hline References & Main topics discussed & Main issues discussed & Main structures included & Main future subjects suggested \\
\hline$[85]$ & $\begin{array}{l}\text { Fog computing, } \\
\text { cloudlets, and mobile } \\
\text { edge computing }\end{array}$ & $\begin{array}{l}\text { High latency, non- } \\
\text { adaptive machine, and } \\
\text { low spectral efficiency }\end{array}$ & $\begin{array}{l}\text { Architectures, principles, } \\
\text { efforts, and applications }\end{array}$ & $\begin{array}{l}\text { Opportunities and concerning } \\
\text { challenges }\end{array}$ \\
\hline$[84]$ & IoT-Cloud based & $\begin{array}{l}\text { Infrastructure, demands, } \\
\text { and services }\end{array}$ & $\begin{array}{l}\text { Fast development of } \\
\text { technologies and the } \\
\text { solutions to the raised issues }\end{array}$ & $\begin{array}{l}\text { Challenges, concerns, and future } \\
\text { trends }\end{array}$ \\
\hline [78] & $\begin{array}{l}\text { Big data for the smart } \\
\text { city }\end{array}$ & $\begin{array}{l}\text { Applications, potential } \\
\text { improvements and the } \\
\text { innovations in smart } \\
\text { cities }\end{array}$ & $\begin{array}{l}\text { Visibility of smart city, data } \\
\text { collection, visualization, and } \\
\text { the infrastructure of the } \\
\text { smart city }\end{array}$ & $\begin{array}{l}\text { Valuable data, processing steps, } \\
\text { smart traffic systems, and big } \\
\text { data applications and platforms }\end{array}$ \\
\hline [81] & Mobile cloud services & $\begin{array}{l}\text { The paradigm of smart } \\
\text { city applications and } \\
\text { projects }\end{array}$ & $\begin{array}{l}\text { Data processing and storage, } \\
\text { sharing data }\end{array}$ & $\begin{array}{l}\text { Criteria used to select mobile } \\
\text { cloud services }\end{array}$ \\
\hline$[83]$ & Cloud IoT & $\begin{array}{l}\text { Energy-efficiency, quick } \\
\text { response time, } \\
\text { performance, reduced } \\
\text { latency, better-localized } \\
\text { accuracy and } \\
\text { performance }\end{array}$ & $\begin{array}{l}\text { The architectural paradigm } \\
\text { of fog nodes such as edge } \\
\text { servers, smart routers, and } \\
\text { base stations has received } \\
\text { computational requests and } \\
\text { sensing information }\end{array}$ & $\begin{array}{l}\text { Applications, facilities of } \\
\text { abstraction, implementations, } \\
\text { and the distributed nature of } \\
\text { multiple providers }\end{array}$ \\
\hline [7] & $\begin{array}{l}\text { Edge computing, fog } \\
\text { computing, and eco- } \\
\text { systems }\end{array}$ & $\begin{array}{l}\text { Architecture, platforms, } \\
\text { characteristics, } \\
\text { applications, and } \\
\text { abstractions }\end{array}$ & $\begin{array}{l}\text { Physical properties, } \\
\text { application mobility, } \\
\text { runtime environment, } \\
\text { privacy sensitivity, and } \\
\text { novel capabilities }\end{array}$ & $\begin{array}{l}\text { Identified challenging issues and } \\
\text { solutions potential possibilities }\end{array}$ \\
\hline [79] & IoT and clouds & $\begin{array}{l}\text { Smart city concept that } \\
\text { plays a vital role in } \\
\text { industrial and academic } \\
\text { fields in smart city } \\
\text { technologies }\end{array}$ & $\begin{array}{l}\text { Many middleware platforms } \\
\text { and infrastructures of IoT } \\
\text { smart city vision to provide } \\
\text { main requirements and } \\
\text { information }\end{array}$ & $\begin{array}{l}\text { Smart city and general } \\
\text { approaches to cloud and sensors } \\
\text { as well as services with the } \\
\text { implementation of cloud and } \\
\text { IoT }\end{array}$ \\
\hline$[6]$ & $\begin{array}{l}\text { The paradigm of IoT } \\
\text { and cloud computing }\end{array}$ & $\begin{array}{l}\text { Opportunities for } \\
\text { analyzing data of } \\
\text { geographic regions to } \\
\text { save life of people }\end{array}$ & $\begin{array}{l}\text { Fog computing services for } \\
\text { efficient analysis and critical } \\
\text { review of IoT data }\end{array}$ & $\begin{array}{l}\text { IoT data and fog computing } \\
\text { real-time applications } \\
\text { opportunities of analyzing data }\end{array}$ \\
\hline
\end{tabular}

Figure 1 shows the classification of the different studies. Some of the researchers discuss advantages and benefits of fog-based smart city applications. Others discuss environment applications, fog computing, architectures and infrastructure, and issues and challenges. Several researchers in [3, 13, 74, 82, 87, 97] studied the advantages and benefits of fog-based smart city applications. The environmental applications of fog-based smart city are discussed in several studies [3, 12, 74, 76, 80, 82, 87]. Fog computing is discussed also by many studies $[12,13,16,76,97]$. The architectures and infrastructure of fog-based smart city are focused in [3, 13, 76, 86, 87, 97]. The study in [76] presented assumptions for environmental applications of fog computing and the architectures and infrastructure of fog computing paradigm, whereas; the authors 
in [87] introduced some challenging issues in the framework of fog computing as well as the advantages and benefits gained by deploying different environmental applications. Other studies such as [82] have studied the resource management, pricing, and heterogeneity issues of fog computing. In addition, the study in [3] discusses internet of things, cloud computing, and cyber-physical systems. Therefore, the authors in [3] reveal that facilitating technologies, functional requirements, classified categories of new technologies, existing essential technologies and practical issues of data processing and software platforms. It is also showed frequent open research issues, future directions and trends of the smart city.

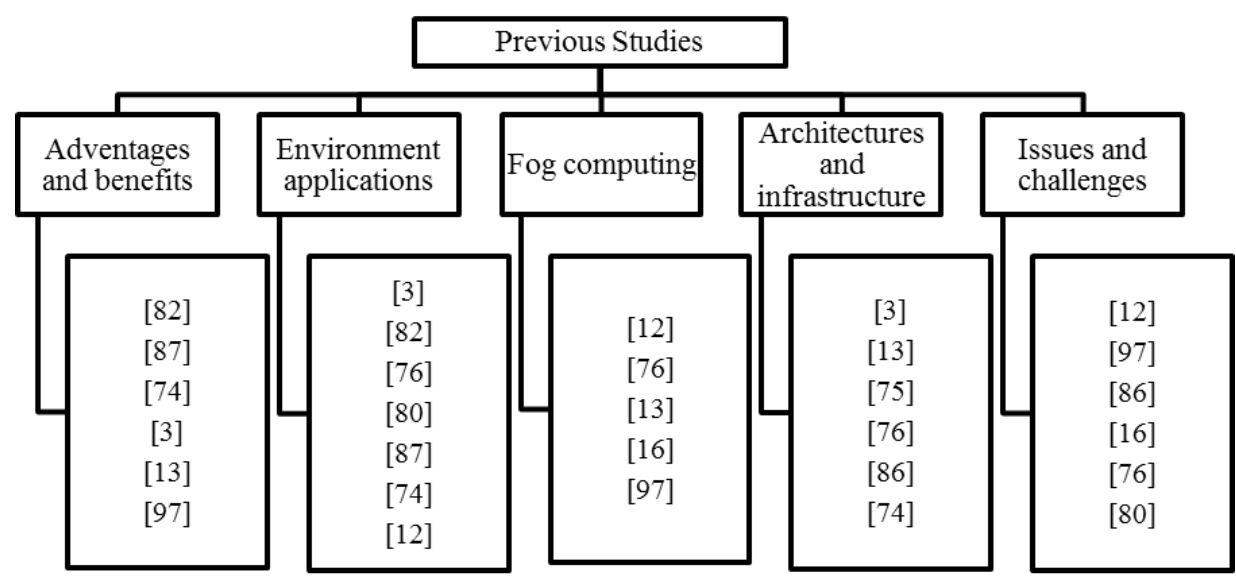

Figure 1. The classification of the different studies and how they introduce the surveys

A summary of the related works that have investigated the application of cloud computing (mainly fog computing) in the smart city considering resource management, pricing, security, privacy, performance, reliability, latency, scheduling, and heterogeneity measures is presented in Table 3. In [82], resources management, pricing, and heterogeneity issues are discussed. The study in [73] presented an overview of pricing, security, privacy, performance, and reliability issues of fog computing. Similarly, the study in [77] presents security, privacy, performance, and reliability issues. However, the study in [6] only discussed the latency and security issues of fog computing applications. Further, the study in [7] only discussed reliability. Most of the studies have investigated the issues of privacy, security, performance, and reliability. Differently, the study in [98] discussed the scheduling issues in fog computing applications, while [99] showed resources management issues.

Table 3. A summary of the related works that have investigated the application of cloud and fog computing in smart city

\begin{tabular}{|c|c|c|c|c|c|c|c|c|}
\hline Ref & $\begin{array}{c}\text { Resources } \\
\text { management }\end{array}$ & Pricing & $\begin{array}{c}\text { Security and } \\
\text { privacy }\end{array}$ & Performance & Reliability & Latency & Scheduling & Heterogeneity \\
\hline$[82]$ & $\sqrt{ }$ & $\sqrt{ }$ & & & & & & $\sqrt{ }$ \\
\hline [73] & & $\sqrt{ }$ & $\sqrt{ }$ & $\sqrt{ }$ & $\sqrt{ }$ & & & \\
\hline [77] & & & $\sqrt{ }$ & $\sqrt{ }$ & $\sqrt{ }$ & & & \\
\hline$[6]$ & & & $\sqrt{ }$ & & & $\sqrt{ }$ & & \\
\hline [7] & & & & & $\sqrt{ }$ & & & \\
\hline [8] & & & & $\sqrt{ }$ & $\sqrt{ }$ & $\sqrt{ }$ & & \\
\hline [15] & $\sqrt{ }$ & & $\sqrt{ }$ & & & $\sqrt{ }$ & & \\
\hline [83] & $\sqrt{ }$ & & & $\sqrt{ }$ & & $\sqrt{ }$ & & \\
\hline [100] & & & & $\sqrt{ }$ & $\sqrt{ }$ & $\sqrt{ }$ & & \\
\hline [101] & & & $\sqrt{ }$ & & $\sqrt{ }$ & & & \\
\hline [102] & & & & & & $\sqrt{ }$ & & $\sqrt{ }$ \\
\hline [103] & $\sqrt{ }$ & & $\sqrt{ }$ & & & & & \\
\hline [104] & $\sqrt{ }$ & & & & & $\sqrt{ }$ & & \\
\hline [12] & & & $\sqrt{ }$ & & $\sqrt{ }$ & $\sqrt{ }$ & & \\
\hline [105] & & & $\sqrt{ }$ & & & & & \\
\hline [99] & $\sqrt{ }$ & & & & & & & \\
\hline [98] & & & $\sqrt{ }$ & & & & $\sqrt{ }$ & \\
\hline
\end{tabular}




\section{CONCLUSION}

Smart cities expected to be grow rapidly, as a result to the cost decreasing and sensing technology increasing. In these cities, there are always unexpected emergencies that have to be treated to maintain the ordinary life and to save citizens liven within. Then a smart system is needed to detect the emergent situations and to deal with them. This surveys the literature on emergent situations of smart cities. We have analyzed and evaluated different aspects of smart cities, cloud, IoT and fog computing. A set of lessons learned are derived based on the literature review. The remaining challenges and corresponding research directions are discussed. In addition, we have discussed the prospects of smart cities with a focus on the emergent situations. However, most of these studies have lack deep knowledge in the critical issues of smart city real-time systems. Our finding obviously affirm the necessity of dealing with emergent situations in smart cities. The limitation of this study is that the limited number of reference that motivates us to more investigates the work in future with more references, especially in latency factor of fog computing and realtime applications.

\section{REFERENCES}

[1] M. Naphade, et al., "Smarter cities and their innovation challenges," Computer, pp. 32-39, 2011.

[2] A. Zanella, et al., "Internet of things for smart cities," IEEE Internet of Things journal, vol. 1, pp. 22-32, 2014.

[3] E. F. Z. Santana, et al., "Software platforms for smart cities: Concepts, requirements, challenges, and a unified reference architecture," ACM Computing Surveys (Csur), vol. 50, pp. 78, 2017.

[4] https://en.wikipedia.org/wiki/Internet_of_things \last visited (March 15, 2018).

[5] I. Almarashdeh, et al., "Developing a Mobile Portal Prototype for E-government Services," Journal of Applied Sciences, vol. 14, pp. 791-797, 2014

[6] A. Rauniyar, et al., "Crowdsourcing-based disaster management using fog computing in internet of things paradigm," Collaboration and Internet Computing (CIC), 2016 IEEE 2nd International Conference on, 2016, pp. 490-494.

[7] P. Varshney and Y. Simmhan, "Demystifying fog computing: Characterizing architectures, applications and abstractions," Fog and Edge Computing (ICFEC), 2017 IEEE 1st International Conference on, 2017, pp. 115-124.

[8] R. Petrolo, et al., "Towards a smart city based on cloud of things," Proceedings of the 2014 ACM international workshop on Wireless and mobile technologies for smart cities, pp. 61-66, 2014.

[9] I. Almarashdeh, et al., "Development of an interactive learning management system for malaysian distance learning institutions," Middle East Journal of Scientific Research, vol. 14, pp. 1471-1479, 2013.

[10] P. Mell and T. Grance, "The NIST definition of cloud computing," 2011.

[11] C. Mouradian, et al., "A comprehensive survey on fog computing: State-of-the-art and research challenges," IEEE Communications Surveys \& Tutorials, vol. 20, pp. 416-464, 2017.

[12] S. Yi, et al., "Fog computing: Platform and applications," 2015 Third IEEE Workshop on Hot Topics in Web Systems and Technologies (HotWeb), pp. 73-78, 2015.

[13] S. Yi, et al., "A survey of fog computing: concepts, applications and issues," Proceedings of the 2015 workshop on mobile big data, pp. 37-42, 2015.

[14] F. Bonomi, et al., "Fog computing and its role in the internet of things," Proceedings of the first edition of the MCC workshop on Mobile cloud computing, pp. 13-16, 2012.

[15] J. Santos, et al., "Fog computing: Enabling the management and orchestration of smart city applications in $5 \mathrm{~g}$ networks," Entropy, vol. 20, pp. 4, 2017.

[16] Weisong Shi, et al., "Edge computing: Vision and challenges," IEEE Internet of Things journal, vol. 3, pp. 637-646, 2016.

[17] M. K. Alsmadi, et al., "Performance Comparison of Multi-layer Perceptron (Back Propagation, Delta Rule and Perceptron) algorithms in Neural Networks," 2009 IEEE International Advance Computing Conference, 2009, pp. 296-299.

[18] Z. Thalji and M. Alsmadi, "Iris Recognition using robust algorithm for eyelid, eyelash and shadow avoiding," World Applied Sciences Journal, vol. 25, pp. 858-865, 2013.

[19] M. Alsmadi, et al., "A High Performance Protocol for Fault Tolerant Distributed Shared Memory (FaTP)," Journal of Applied Sciences, vol. 13, pp. 790-799, 2013.

[20] F. Haddad, et al., "Hotelling's t ${ }^{2}$ charts using winsorized modified one step m-estimator for individual non normal data," Journal of Theoretical \& Applied Information Technology, vol. 72, pp. 215-226, 2015.

[21] F. Haddad and M. K. Alsmadi, "Improvement of The Hotelling's T2 Charts Using Robust Location Winsorized One Step M-Estimator (WMOM),"Journal of Mathematics, vol. 50, pp. 97-112, 2018.

[22] M. K. Alsmadi, et al., "Server Failures Enabled Javaspaces Service," Journal of Computer Science, vol. 10, pp. 671-679, 2014.

[23] M. K. Alsmadi, "Apparatus and method for lesions segmentation,” ed: US Patent App. 15/614,893, 2018.

[24] M. K. Alsmadi, "Facial expression recognition," ed: Google Patents, 2018.

[25] R. Aldaej, et al., "Analyzing, Designing and Implementing a Web-Based Auction online System," International Journal of Applied Engineering Research, vol. 13, pp. 8005-8013, 2018.

[26] H. Almaimoni, et al., "Developing and Implementing WEB-based Online Destination Information Management System for Tourism," International Journal of Applied Engineering Research, vol. 13, pp. 7541-7550, 2018. 
[27] I. A. Almrashdeh, et al., "Requirement analysis for distance learning management system students in Malaysian universities," Journal of Theoretical and Applied Information Technology, vol. 24, pp. 17-27, 2011.

[28] M. K. Alsmadi, et al., "Proposed method to decide the appropriate feature set for fish classification tasks using Artificial Neural Network and Decision Tree," IJCSNS vol. 9, pp. 297-301, 2009.

[29] N. Alsubaie, et al., "Analyzing and Implementing an Online Metro Reservation System," International Journal of Applied Engineering Research, vol. 13, pp. 9198-9206, 2018.

[30] D. A. D. Alkhaldi, et al., "Developing and Implementing Web-based Online University Facilities Reservation System," International Journal of Applied Engineering Research, vol. 13, pp. 6700-6708, 2018.

[31] I. Almarashdeh, et al., "Real-Time Elderly Healthcare Monitoring Expert System Using Wireless Sensor Network," International Journal of Applied Engineering Research, vol. 13, pp. 3517-3523, 2018.

[32] M. K. S. Al Smadi, "Fish Classification Using Perceptron Neural Network," Centre for Graduate Studies, Universiti Utara Malaysia, 2007.

[33] M. K. Alsmadi and U. A. Badawi, "Pattern matching in Rotated Images Using Genetic Algorithm," Journal of King Abdulaziz University Computing and Information, vol. 5, pp. 53-59, 2017.

[34] S. Aldossary, et al., "Analyzing, Designing And Implementing A Web-Based Command Center System," International Research Journal of Engineering and Technology, vol. 6, pp. 1008-1019, 2019.

[35] R. A. Sheikh, et al., "Developing and Implementing a Barcode Based Student Attendance System," International Research Journal of Engineering and Technology, vol. 6, pp. 497-506, 2019.

[36] A. A. Abbas, et al., "Analyzing and Implementinga System For Reporting, Follow Up and Resolving of Complaints," International Research Journal of Engineering and Technology, vol. 6, pp. 1833-1842, 2019.

[37] S. A. S. Ali, et al., "Determinants of deposit of commercial banks in Sudan: an empirical investigation (1970-2012)," International Journal of Electronic Finance, vol. 9, pp. 230-255, 2019.

[38] L. Eljawad, et al., "Arabic Voice Recognition Using Fuzzy Logic and Neural Network," International Journal of Applied Engineering Research, vol. 14, pp. 651-662, 2019.

[39] I. Almarashdeh, et al., "Search Convenience and Access Convenience: The Difference Between Website Shopping and Mobile Shopping," International Conference on Soft Computing and Pattern Recognition, 2018, pp. 33-42.

[40] I. Al-Marashdeh, et al., "An Elite Pool-Based Big Bang-Big Crunch Metaheuristic for Data Clustering," Journal of Computer Science, vol. 14, pp. 1611-1626, 2018.

[41] M. K. Alsmadi, "A hybrid firefly algorithm with fuzzy-C mean algorithm for MRI brain segmentation," American Journal of Applied Sciences, vol. 11, pp. 1676-1691, 2014.

[42] M. K. Alsmadi, "MRI brain segmentation using a hybrid artificial bee colony algorithm with fuzzy-c mean algorithm," Journal of Applied Sciences, vol. 15, pp. 100, 2015.

[43] M. K. Alsmadi, "A hybrid Fuzzy C-Means and Neutrosophic for jaw lesions segmentation," Ain Shams Engineering Journal, 2017.

[44] S. H. Park and K. Han, "Methodologic Guide for Evaluating Clinical Performance and Effect of Artificial Intelligence Technology for Medical Diagnosis and Prediction," Radiology, pp. 171920, 2018.

[45] D. S. Kermany, et al., "Identifying Medical Diagnoses and Treatable Diseases by Image-Based Deep Learning," Cell, vol. 172, pp. 1122-1131, 2018.

[46] G. M. Jaradat, et al., "Hybrid Elitist-Ant System for Nurse-Rostering Problem," Journal of King Saud UniversityComputer and Information Sciences, 2018.

[47] M. Rasmi, et al., "Healthcare professionals' acceptance Electronic Health Records system: Critical literature review (Jordan case study)," International Journal of Healthcare Management, pp. 1-13, 2018.

[48] M. K. Alsmadi, "Forecasting River Flow in the USA Using a Hybrid Metaheuristic Algorithm with Back-Propagation Algorithm," Scientific Journal of King Faisal University (Basic and Applied Sciences), vol. 18, pp. 13-24, 2017.

[49] J. Adeyemo, et al., "River Flow Forecasting Using an Improved Artificial Neural Network," EVOLVE-A Bridge between Probability, Set Oriented Numerics, and Evolutionary Computation VI, ed: Springer, pp. 179-193, 2018.

[50] A. Ahani, et al., "Performance Assessment of the Linear, Nonlinear and Nonparametric Data Driven Models in River Flow Forecasting," Water Resources Management, pp. 1-17, 2018.

[51] A. M. Al Smadi, et al., "Accessing Social Network Sites Using Work Smartphone for Face Recognition and Authentication," Research Journal of Applied Sciences, Engineering and Technology, vol. 11, pp. 56-62, 2015.

[52] M. Alsmadi, "Facial recognition under expression variations," Int. Arab J. Inf. Technol., vol. 13, pp. 133-141, 2016.

[53] M. Alsmadi, et al., Fish Classification: Fish Classification Using Memetic Algorithms with Back Propagation Classifier, LAP LAMBERT Academic Publishing, 2012.

[54] M. Alsmadi, et al., "A hybrid memetic algorithm with back-propagation classifier for fish classification based on robust features extraction from PLGF and shape measurements," Information Technology Journal, vol. 10, pp. 944-954, 2011.

[55] M. Alsmadi, et al., "Fish Recognition Based on Robust Features Extraction from Size and Shape Measurements Using Neural Network," Journal of Computer Science, vol. 6, pp. 1088-1094, 2010.

[56] M. K. Alsmadi, "An efficient similarity measure for content based image retrieval using memetic algorithm," Egyptian Journal of Basic and Applied Sciences, vol. 4, no. 2, pp. 112-122, Jun 2017.

[57] M. K. Alsmadi, "Query-sensitive similarity measure for content-based image retrieval using meta-heuristic algorithm," Journal of King Saud University-Computer and Information Sciences, vol. 30, no. 3, pp. 373-381, 2018.

[58] M. K. Alsmadi, et al., "Face Image Recognition Based On Partial Face Matching Using Genetic Algorithm," SUST Journal of Engineering and Computer Sciences (JECS), vol. 18, pp. 51-61, 2017. 
[59] M. K. Alsmadi, et al., "Fish recognition based on robust features extraction from color texture measurements using back-propagation classifier," Journal of Theoritical and Applied Information Technology, vol. 18, 2010.

[60] U. A. Badawi and M. K. Alsmadi, "A General Fish Classification Methodology Using Meta-Heuristic Algorithm With Back Propagation Classifier," Journal of Theoretical \& Applied Information Technology, vol. 66, pp. 803-812, 2014.

[61] M. Yousuf, et al., "A Novel Technique Based on Visual Words Fusion Analysis of Sparse Features for Effective Content-Based Image Retrieval," Mathematical Problems in Engineering, vol. 2018, 2018.

[62] R. R. Saritha, et al., "Content based image retrieval using deep learning process," Cluster Computing, pp. 1-14, 2018.

[63] T. H. Farag, et al., "Extended Absolute Fuzzy Connectedness Segmentation Algorithm Utilizing Region and Boundary-Based Information," Arabian Journal for Science and Engineering, pp. 1-11, 2017.

[64] M. K. Alsmadi, "A hybrid Fuzzy C-Means and Neutrosophic for jaw lesions segmentation," Ain Shams Engineering Journal, vol. 9, no. 4, pp. 697-706, Dec 2018.

[65] U. A. Badawi and M. K. S. Alsmadi, "A Hybrid Memetic Algorithm (Genetic Algorithm and Great Deluge Local Search) With Back-Propagation Classifier for Fish Recognition," International Journal of Computer Science Issues, vol. 10, pp. 348-356, 2013.

[66] A. M, O. K and N. S., "Back Propagation Algorithm: The Best Algorithm Among the Multi-layer Perceptron Algorithm," International Journal of Computer Science and Network Security, vol. 9, pp. 378-383, 2009.

[67] M. Sharma, et al., "Information Retrieves from Brain MRI Images for Tumor Detection Using Hybrid Technique K-means and Artificial Neural Network (KMANN)," Networking Communication and Data Knowledge Engineering, ed: Springer, pp. 145-157, 2018.

[68] Y. Gao, et al., "An enhanced artificial bee colony optimizer and its application to multi-level threshold image segmentation," Journal of Central South University, vol. 25, pp. 107-120, 2018.

[69] M. K. Alsmadi, et al., "Fish classification based on robust features extraction from color signature using backpropagation classifier," Journal of Computer Science, vol. 7, pp. 52, 2011.

[70] I. Almarashdeh, et al., "Looking Inside and Outside the System: Examining the Factors Influencing Distance Learners Satisfaction in Learning Management System," Journal of Computer Science, 2018.

[71] I. Almarashdeh, "The Important of Service Quality and the Trust in Technology on Users Perspectives to Continues use of Mobile Services," Journal of Theoretical \& Applied Information Technology, vol. 96, 2018.

[72] A. B. Rjab and S. Mellouli, "Smart cities in the era of artificial intelligence and internet of things: literature review from 1990 to 2017," Proceedings of the 19th Annual International Conference on Digital Government Research: Governance in the Data Age, Delft, The Netherlands, 2018.

[73] A. Botta, et al., "Integration of cloud computing and internet of things: a survey," Future Generation Computer Systems, vol. 56, pp. 684-700, 2016.

[74] S. Sivakumar, et al., "Survey on Integration of Cloud Computing and Internet of Things Using Application Perspective," International Journal of Emerging Research in Management \& Technology, vol. 6, pp. 101-108, 2017.

[75] A. V. Anttiroiko, et al., "Smart cities in the new service economy: building platforms for smart services," AI \& society, vol. 29, pp. 323-334, 2014.

[76] D. P. Abreu, et al., "A resilient Internet of Things architecture for smart cities," Annals of Telecommunications, vol. 72, pp. 19-30, 2017.

[77] M. Hussain, et al., "Fog Computing in IoT Aided Smart Grid Transition-Requirements, Prospects, Status Quos and Challenges," arXiv preprint arXiv:1802.01818, 2018.

[78] I. A. T. Hashem, et al., "The role of big data in smart city," International Journal of Information Management, vol. 36, pp. 748-758, 2016.

[79] R. Petrolo, et al., "Towards a smart city based on cloud of things, a survey on the smart city vision and paradigms," Transactions on Emerging Telecommunications Technologies, vol. 28, pp. e2931, 2017.

[80] H. Arasteh, et al., "Iot-based smart cities: a survey," Environment and Electrical Engineering (EEEIC), 2016 IEEE 16th International Conference on, 2016, pp. 1-6.

[81] M. S. Sneppe, D. Namiot, "On mobile cloud for smart city applications," arXiv preprint arXiv:1605.02886, 2016.

[82] J. F. Hernandez, et al., "Infrastructure of Services for a Smart City using Cloud Environment." International Journal of Computer Networks \& Communications (IJCNC), vol. 8, no. 1, Jan 2016

[83] A. Munir, et al., "IFCIoT: Integrated Fog Cloud IoT: A novel architectural paradigm for the future Internet of Things," IEEE Consumer Electronics Magazine, vol. 6, pp. 74-82, 2017.

[84] J. Gubbi, et al., "Internet of Things (IoT): A vision, architectural elements, and future directions," Future Generation Computer Systems, vol. 29, pp. 1645-1660, 2013.

[85] Y. Ai, et al., "Edge computing technologies for Internet of Things: a primer," Digital Communications and Networks, vol. 4, pp. 77-86, 2018.

[86] S. Ijaz, et al., "Smart cities: A survey on security concerns," International Journal of Advanced Computer Science and Applications, vol. 7, pp. 612-625, 2016.

[87] A. Gharaibeh, et al., "Smart cities: A survey on data management, security, and enabling technologies," IEEE Communications Surveys \& Tutorials, vol. 19, pp. 2456-2501, 2017.

[88] P. Hayat, "Smart Cities: a global perspective,” India Quarterly, vol. 72, pp. 177-191, 2016.

[89] T. Brandt, et al., "Smart Cities and the Role of IS Research in Improving Urban Life," Thirty Seventh International Conference on Information Systems, Dublin, 2016. 
[90] H. Ye, "Research on emergency resource scheduling in smart city based on HPSO algorithm," Issues, 2016.

[91] Á. Asensio, et al., "Managing emergency situations in the smart city: The smart signal," Sensors, vol. 15, pp. 14370-14396, 2015.

[92] S. Ghosh and A. Gosavi, "A semi-Markov model for post-earthquake emergency response in a smart city," Control Theory and Technology, vol. 15, pp. 13-25, 2017.

[93] Z. Alazawi, et al., "A smart disaster management system for future cities," Proceedings of the 2014 ACM international workshop on wireless and mobile technologies for smart cities, pp. 1-10, 2014.

[94] S. Wan, et al., "To Smart City: Public Safety Network Design for Emergency," IEEE Access, vol. 6, pp. 1451-1460, 2018.

[95] R. Srinivasan, et al., "Privacy conscious architecture for improving emergency response in smart cities," Smart City Security and Privacy Workshop (SCSP-W), pp. 1-5, 2016.

[96] S. Djahel, et al., "Reducing emergency services response time in smart cities: An advanced adaptive and fuzzy approach," Smart Cities Conference (ISC2), 2015 IEEE First International, 2015, pp. 1-8.

[97] S. Yi, et al., "Security and privacy issues of fog computing: A survey," International conference on wireless algorithms, systems, and applications, 2015, pp. 685-695.

[98] M. Sookhak, et al., "Fog vehicular computing: Augmentation of fog computing using vehicular cloud computing," IEEE Vehicular Technology Magazine, vol. 12, pp. 55-64, 2017.

[99] J. Wang, et al., "Elastic urban video surveillance system using edge computing," Proceedings of the Workshop on Smart Internet of Things, pp. 7, 2017.

[100] B. R. Stojkoska, et al., "Internet of things framework for home care systems," Wireless Communications and Mobile Computing, vol. 2017, 2017.

[101] S. Basudan, et al., "A privacy-preserving vehicular crowdsensing-based road surface condition monitoring system using fog computing," IEEE Internet of Things journal, vol. 4, pp. 772-782, 2017.

[102] T. N. Gia, et al., "Fog computing in healthcare internet of things: A case study on ecg feature extraction," Computer and Information Technology; Ubiquitous Computing and Communications; Dependable, Autonomic and Secure Computing; Pervasive Intelligence and Computing (CIT/IUCC/DASC/PICOM), 2015 IEEE International Conference on, 2015, pp. 356-363.

[103] G. Ermacora, et al., "A cloud robotics architecture for an emergency management and monitoring service in a smart city environment," Polytech. Univ. Turin, Turin, Italy, Tech. Rep, 2013.

[104] R. Mayer, et al., "The fog makes sense: Enabling social sensing services with limited internet connectivity," Proceedings of the 2nd International Workshop on Social Sensing, pp. 61-66, 2017.

[105] X. Wang and Z. Li, "Traffic and Transportation Smart with Cloud Computing on Big Data," IJCSA, vol. 13, pp. 1-16, 2016. 